\title{
O PAPEL DA ONU NA GOVERNANÇA ECONÔMICA GLOBAL DO PÓS-GUERRA*
}

\author{
Patrícia Nogueira Rinaldi**
}

\begin{abstract}
Resumo: $\mathrm{O}$ artigo discute o papel da ONU na governança econômica global do pósguerra, considerando o nexo institucional do liberalismo inserido, forjado pelo bloco histórico internacional transatlântico. Enquanto o mandato econômico da ONU foi relegado ao segundo plano devido à autonomia das Instituições de Bretton Woods, a organização tornou-se um espaço importante não apenas para as demandas Terceiro Mundo, mas de criação de uma nova ideologia que questionava o propósito social do liberalismo inserido.
\end{abstract}

Palavras-chave: ONU. Instituições de Bretton Woods. Terceiro Mundo. Liberalismo inserido.

The UN's role in global economic governance post-war

Abstract: This paper discusses the role of the UN in the global economic governance during the post-war period, considering the institutional nexus of the embedded liberalism, forged by the transatlantic international historic bloc. Whereas the economic mandate of the UN was relegated to the background due to the autonomy of the Bretton Woods Institutions, the organization has become an important forum, not only to the Third World demands, but to the creation of a new ideology that questioned the social purpose of the embedded liberalism.

Keywords: UN. Bretton Woods institutions. Third World. Embedded liberalism.

El papel de la ONU en la gobernanza económica global del post-guerra

\footnotetext{
* Gostaria de agradecer os pertinentes comentários e sugestões dos pareceristas, que contribuíram enormemente para a discussão do tema.

** Instituto de Filosofia e Ciências Humanas, Universidade Estadual de Campinas - Unicamp, Campinas-SP, Brasil (pnrinaldi@gmail.com).

Recebido em: 26/11/2014 - Aceito em: 02/06/2015.
} 
|208|

O papel da ONU na governança...

Resumen: El artículo discute el papel de la ONU en la gobernanza económica global del post-guerra, considerando el nexo institucional del liberalismo insertado, forjado por el bloque histórico internacional transatlántico. Mientras que el mandato económico de la ONU se relegó a un segundo plano debido a la autonomía de las Instituciones de Bretton Woods, la organización se ha convertido en un espacio importante no sólo para las demandas del Tercer Mundo, pero creando una nueva ideología que cuestionaba el propósito social del liberalismo insertado.

Palabras clave: ONU. Instituciones de Bretton Woods. Tercer Mundo. Liberalismo insertado.

\section{Introdução}

A Carta de São Francisco, instrumento que marca a criação da Organização das Nações Unidas (ONU) em 1945, prevê a essa organização um mandato econômico de atuação. Por meio do Conselho Econômico e Social (ECOSOC), a ONU deveria atuar como coordenadora das chamadas Instituições de Bretton Woods (IBW), a saber, o Fundo Monetário Internacional (FMI) e o Banco Mundial. Entretanto, no desdobramento prático das relações econômicas internacionais do chamado pós-guerra (período de 1945-1970), a ONU foi afastada de um papel predominante na governança econômica global. Isso porque a ordem econômica estabelecida pelo bloco histórico internacional transatlântico liderado pelos Estados Unidos (EUA) - chamada de liberalismo inserido - fragmentou-se institucionalmente nas IBW, fóruns nos quais os países desenvolvidos poderiam controlar os rumos econômicos globais segundo seus interesses.

Mas o liberalismo inserido compreendia um compromisso de classes que possibilitava algumas medidas de autonomia nacional, resultando na articulação de forças de resistência no interior da ONU. A criação da UNCTAD e do G-77, em 1964, e a proposta da Nova Ordem Econômica Internacional, em 1974, contrapõem-se diretamente à tentativa do bloco histórico internacional transatlântico em excluir dos arranjos decisivos da governança econômica global do pós-guerra não apenas a ONU, mas os países em desenvolvimento que compunham o chamado Terceiro Mundo. 
Considerando que as organizações internacionais são sínteses institucionais do embate entre diferentes forças sociais no âmbito internacional, o artigo apresentará o nexo institucional do liberalismo inserido a partir do mandato econômico previsto para a ONU. O objetivo é enfatizar que, mesmo afastada de um papel predominante, a ONU tornou-se um espaço crucial de inserção do Terceiro Mundo e de criação de uma nova ideologia que questionava os propósitos sociais do liberalismo inserido.

\section{O liberalismo inserido: hegemonia americana e o bloco histórico internacional transatlântico}

Um dos poucos consensos entre as principais correntes teóricas das relações internacionais refere-se ao papel central dos EUA na configuração da governança econômica global no pós-guerra. Porém, há uma variedade de interpretações, mais ou menos complementares, sobre a forma e o conteúdo em que se deu a atuação estadunidense.

Uma das teorias mais difundidas é a da estabilidade hegemônica, que afirma, de forma geral, que uma ordem econômica internacional de características liberais é estabelecida quando há um hegemon, como foi o caso dos EUA no período. A estabilidade econômica garantida pelo hegemon permite a ampliação das forças de mercado, ao invés de reprimi-las (KINDLEBERGER, 1973 :28).

Embora tal interpretação não seja equivocada, ela não analisa o propósito social e as forças sociais que sustentam tal ordem, elementos cruciais para compreender o papel das organizações econômicas internacionais. Para discutir tais pontos, a seção detém-se na análise de Ruggie (1983) sobre o propósito social do regime internacional estabelecido no pós-guerra, denominado liberalismo inserido; e de Gill e Law (2007) sobre o bloco histórico internacional transatlântico que sustentou tal regime ${ }^{1}$.

\footnotetext{
${ }^{1} \mathrm{O}$ artigo não tem a pretensão de executar qualquer conciliação teórica entre
} as duas interpretações (sendo Ruggie considerado construtivista, e Gill e 
|210 |

O papel da ONU na governança...

A ordem econômica do pós-guerra não é resultado de um mero cômputo de forças favorável aos EUA, como indica a teoria da estabilidade hegemônica. Ruggie (1983:198) aponta que, enquanto o poder prevê a forma de uma ordem internacional, apenas o propósito social expressa seu conteúdo.

O termo liberalismo inserido caracteriza o propósito social da ordem econômica do pós-guerra, de conciliação entre o multilateralismo e a estabilidade interna, garantindo a internacionalização da autoridade política dos EUA. Esse país proveu os recursos materiais necessários e ocupou o papel de negociador principal do propósito social de tal ordem, obviamente moldando-a segundo seus interesses: o multilateralismo econômico permitiu que o dólar e se tornasse a moeda de paridade com o ouro; e a liberalização econômica beneficiou os mercados americanos.

Além de promover a abertura econômica internacional, o liberalismo inserido traz uma configuração inédita, que é a capacidade de atender a estabilidade doméstica ao constituir mecanismos de intervenção estatal que buscavam regular os mercados e minimizar os custos sociais da liberalização. Embora os EUA fizessem as regras da ordem econômica, essas eram implementadas com alguma autonomia pelos Estados, daí a ideia de compromisso que envolve o liberalismo inserido:

\footnotetext{
diferentemente do nacionalismo econômico da década de 1930, ele seria multilateral em seu caráter; e diferentemente do liberalismo do padrão ouro e do livre comércio, seu multilateralismo seria regido pelo intervencionismo doméstico² (RUGGIE, 1983: 209, trad. nossa).
}

\footnotetext{
Law, neogramscianos), mas apontar o caráter complementar dos conceitos desenvolvidos por esses autores dentro de suas respectivas abordagens.

${ }^{2}$ Do original: "unlike the economic nationalism of the thirties, it would be multilateral in character; unlike the liberalism of the gold standard and free trade, its multilateralism would be predicated upon domestic interventionism".
} 
O compromisso permite a articulação de forças sociais, mecanismos e instituições de produção e troca que se relacionam nos planos nacional e internacional. Dá-se o nome de bloco histórico internacional ao compromisso social que cimenta uma ordem internacional, entendido como a "congruência histórica entre forças materiais, instituições e ideologias ou, de modo geral, a uma aliança entre diferentes forças de classe" (GILL; LAW, 2007: 158). O bloco efetiva-se com a existência de um Estado cuja classe hegemônica é a dominante, capaz de manter a coesão, a identidade e a organização política dentro do bloco ao propagar um conjunto de ideias hegemônicas, consideradas universais, que harmonizam seus interesses com os das classes não hegemônicas ou subordinadas.

No pós-guerra, o bloco histórico centrou-se na internacionalização de forças sociais emergentes dos EUA, permitindo uma conexão transatlântica. Reuniu frações do capital produtivo americano organizado sob a forma fordista de acumulação e permitiu sua expansão por meio das novas oportunidades de exportação e investimentos diretos em países estrangeiros, tanto na manufatura quanto na indústria extrativista, principalmente do petróleo. Também estavam presentes frações do capital financeiro, representadas por Wall Street, que buscavam oportunidades de investimentos e um papel internacional proeminente para o dólar (GILL; LAW, 2007: 161-2).

Porém, tanto a consolidação do bloco soviético quanto as demandas sociais dos trabalhadores dos países desenvolvidos (legitimadas pela destruição trazida pela guerra), geraram grupos opositores ao bloco histórico internacional. Para conciliar essa oposição, tal bloco acabou reunindo elementos dos aparatos de Estado, partidos políticos de centro e associações não comunistas de trabalhadores, para os quais a estabilidade doméstica era crucial.

A partir dessas considerações, será tratado o papel das organizações econômicas internacionais para a efetivação do liberalismo inserido no pós-guerra. 
|212 |

O papel da ONU na governança...

O nexo institucional do liberalismo inserido: as instituições de Bretton Woods

O liberalismo inserido apresentou forte nexo institucional, calcado em normas, regras, princípios e procedimentos que permitiram a convergência de expectativas e a previsibilidade do comportamento dos atores nas relações econômicas internacionais. A essa configuração institucional, Krasner (1983:1) dá o nome de regime internacional, entendido como instituições sociais que materializam a internacionalização de uma autoridade política.

A Conferência de Bretton Woods, ocorrida em julho de 1944, é o marco histórico da institucionalização do liberalismo inserido como regime internacional. Entretanto, mesmo com a presença de 44 países na conferência, o acordo foi a síntese da luta entre o antigo imperialismo inglês e o emergente imperialismo estadunidense, tendo prevalecido os interesses dos EUA.

A aliança anglo-americana ocorreu ainda durante a guerra. Na Carta do Atlântico, de 1941, Churchill e Roosevelt definiram não apenas as diretrizes para o fim do conflito mundial, mas os princípios multilaterais que orientariam a reconstrução econômica global. Porém, enquanto a Inglaterra desejava manter seu poder econômico por meio da assistência à reconstrução, os EUA queriam garantir sua dominância monetária e financeira (VELASCO E CRUZ, 2005: 7).

Durante Bretton Woods, tais diferenças foram sintetizadas no famoso debate entre John Maynard Keynes, então assessor do Ministério da Fazenda inglês, e Harry Dexter-White, representante do Departamento do Tesouro. Dexter-White aproximou os setores financeiros privados, ansiosos por um papel proeminente do dólar e por uma economia internacional aberta, enquanto Keynes lutou para manter os mecanismos de proteção das economias nacionais das crises externas (LICHTENSZTEJN; BAER, 1987: 26).

$\mathrm{O}$ resultado da conferência foi a conciliação entre uma economia internacional aberta e certa autonomia nacional. A autonomia expressou-se, por um lado, pelo regime de câmbio estável, pautado na paridade com o dólar, e pelo controle 
centralizado do comércio e das taxas de câmbio, capaz de manter o equilíbrio dos balanços de pagamento. Por outro, garantiu aos Estados nacionais um espaço para a consolidação de políticas de planejamento e intervenção econômica, voltada principalmente para a expansão industrial, combinadas com políticas de pleno emprego e expansão dos programas proteção social, sintetizados na ideia de Estado de Bem-Estar Social.

Ademais, houve o estabelecimento de uma dupla institucionalização, por meio da criação do FMI e do Banco Mundial $^{3}$, que visavam, respectivamente, assegurar a estabilidade monetária e financeira e garantir os investimentos que sustentassem o crescimento econômico.

Como aponta Murphy (1994: 42), as organizações internacionais compreendem mecanismos regulatórios cruciais para a manutenção do bloco histórico internacional, mobilizando governos e outras forças sociais por meios coercitivos ou consensuais, em âmbito global, regional e nacional. Mas a especificidade das IBW é que elas foram definidas por uma clara relação de desequilíbrio, expressa pelo poder dos EUA no interior do bloco histórico internacional transatlântico.

Tome-se o caso do FMI. A proposta era que o Fundo fosse uma instituição autônoma e imparcial, capaz de corrigir os desequilíbrios mundiais entre os países deficitários e superavitários por meio da promoção do crescimento e do emprego. Entretanto, na conferência de Bretton Woods, Dexter-White garantiu o poder dos EUA na estruturação do FMI: o cargo de vice-diretor geral seria sempre ocupado por um americano; e no sistema de votos, definiu-

\footnotetext{
${ }^{3}$ Usa-se aqui, de forma geral, o nome Banco Mundial, mas é importante salientar que o banco surge como o Banco Internacional para a Reconstrução e Desenvolvimento (BIRD). A partir da década de 1950, novas instituições são adicionadas ao BIRD: a Corporação Financeira Internacional (1956); a Associação Internacional de Desenvolvimento (1960); o Centro Internacional para Solução de Disputas de Investimentos (1965); e a Agência Multilateral de Garantia de Investimentos (1985). Atualmente, essas cinco instituições formam o Grupo Banco Mundial.
} 
se a utilização de cotas equivalentes ao tamanho da contribuição dos países-membros ao Fundo. Obviamente, aos EUA foram designadas as maiores cotas, correspondendo, em 1951, a 33,7\% do total (LICHTENSZTEJN; BAER, 1987: 63).

Ações de transformação do mandato do FMI foram igualmente tomadas, procurando limitar suas responsabilidades em relação aos países superavitários. Isso foi feito por reinterpretações dos artigos constitutivos referentes aos empréstimos concedidos a países com restrições em balanço de pagamentos, relacionando-os a condicionalidades e reformas estruturais, prática que paulatinamente se consolidou nas decisões dos diretores executivos. O mandato do FMI foi reduzido à garantia do padrão dólar-ouro por meio de ajustes ortodoxos aos países subdesenvolvidos, como foi o caso dos países latino-americanos na década de $1950^{4}$ (RUGGIE, 1983: 222-3).

Os mesmos procedimentos são verificados na definição do mandato do Banco Mundial. Essa instituição teria o papel de realizar empréstimos anticíclicos, e pela primeira vez haveria uma instituição pública internacional responsável por prover capital de investimento, suplementando os mecanismos de mercado. Entretanto, foigarantida ainfluência dosEUAnas decisões doBanco, a começar pelo fato de que a presidência seria permanentemente americana (LICHTENSZTEJN; BAER, 1987: 159). Também houve a manutenção do sistema de cotas: os EUA representavam 86,5\% dos recursos do Banco em 1950, o que lhes dava uma espécie de poder de veto virtual já que as decisões requeriam uma maioria de dois terços. Quanto ao destino dos empréstimos, nas décadas de 1950-60 estes visavam atender a três interesses americanos: efetivar uma economia mundial aberta; garantir a atuação dos mercados privados e de outros países industrializados no fornecimento de

\footnotetext{
4 A capacidade do FMI de enquadrar os países subdesenvolvidos foi estabelecida desde o pós-guerra, não se tratando de uma característica exclusiva dos anos 1990, quando o Fundo teve um papel crucial nas reformas neoliberais dos países periféricos.
} 
crédito à assistência econômica; e apoiar os países de importância para os EUA (GWIN, 1997: 209).

A influência americana também foi forte no comércio mundial, mas em um movimento inverso. Em Bretton Woods arquitetou-se o projeto da Organização Internacional do Comércio (OIC), que seria responsável pela liberalização do comércio mundial. Mas as forças conservadoras no Congresso americano, interessadas na manutenção de políticas tarifárias, levaram à nãoratificação do tratado constitutivo da OIC, inviabilizando sua criação. Assim, 23 países decidiram adotar apenas o capítulo 4 da Carta de Havana, referente às negociações de tarifas e regras de comércio, passando a ser chamado de GATT - Acordo Geral de Tarifas e Comércio (THORSTENSEN, 2001: 30).

Embora não fosse uma organização internacional estrito senso, o GATT foi um fórum de negociação, criação e supervisão de normas comerciais, com base no princípio da nação mais favorecida, que dava aos membros um tratamento de não discriminação e reciprocidade. Privilegiando o acesso à exportação de manufaturas do bloco transatlântico internacional, o GATT apresentava poucas exceções, como o caso do Artigo XVIII, que tolerava a proteção da indústria nascente.

A tripla institucionalização da governança econômica global do período - pelo FMI, o Banco Mundial e o GATT - apresenta uma proposital fragmentação. Segundo Benvenisti e Downs (2007: 597-8, trad. nossa), a fragmentação "é em parte o resultado de uma estratégia calculada pelos Estados fortes para criar uma ordem jurídica que reflete seus interesses e que só eles têm a capacidade de alterar" ${ }^{\prime \prime}$. No pós-guerra, os EUA e seu bloco transatlântico puderam usar a fragmentação das responsabilidades nessas três instituições para pressionar, por diferentes instrumentos, os governos nacionais - especialmente dos países menos

\footnotetext{
${ }^{5}$ Do original: "is in part the result of a calculated strategy by powerful states to create a legal order that both closely reflects their interests and that only they have the capacity to alter".
} 
$|216|$

O papel da ONU na governança...

desenvolvidos - à manterem-se vinculados ao quadro mais amplo de liberalização.

A essa fragmentação soma-se o mandato econômico da ONU, definido alguns meses após o término da Conferência de Bretton Woods, e que será discutido na seção seguinte.

\section{A criação da ONU e seu mandato econômico vis-à-vis as Instituições de Bretton Woods}

A Carta do Atlântico, além de prever os pilares para a reconstrução econômica do pós-guerra, mencionava a necessidade de construir um sistema de segurança coletiva para prevenir conflitos internacionais. A partir desse interesse, os EUA e o Reino Unido lideraram 26 países na Conferência de Washington, em 1942, estabelecendo a necessidade de uma solidariedade entre as Nações Unidas ${ }^{6}$ para fazer frente ao Eixo (SEITENFUS, 2012: 127).

Tal solidariedade consolidou-se em outubro de 1944, quando o projeto original da ONU foi elaborado em Dumbarton Oaks. O documento, redigido pelo Departamento de Estado americano, baseava a nova organização no princípio da igualdade soberana, com o propósito de manter a paz e a segurança internacionais pela constituição de um Conselho de Segurança (CSNU)7 ${ }^{7}$. O documento também previa à ONU um mandato econômico, ao reconhecer

\footnotetext{
${ }^{6}$ Foi a primeira vez que a expressão Nações Unidas foi utilizada, inspirando o nome da organização internacional que seria criada em 1945.

${ }^{7} \mathrm{Na}$ Conferência de Yalta, de janeiro de 1945, Churchill, Roosevelt e Stalin definiram a característica principal do CSNU: a diferenciação entre membros permanentes e rotativos, bem como o chamado poder de veto dos primeiros. Essa diferenciação foi criticada pelos países pequenos e médios, como alguns Estados latino-americanos e a Austrália, por estar em contradição com o princípio de igualdade soberana. Porém, essa configuração garantiu o comprometimento das grandes potências com as decisões da ONU (SEITENFUS, 2012: 129-30).
} 
os vínculos entre a paz, a segurança e o bem-estar econômico (SEITENFUS, 2012: 128).

Embora tal mandato fosse previsto, ele estava claramente em segundo plano. O documento sugeria a criação de um Conselho Econômico e Social (ECOSOC) subordinado à Assembleia Geral (AGNU). Porém, a insistência dos pequenos e médios Estados fez com que, nos trabalhos preparatórios para a Conferência de São Francisco, tal Conselho tivesse caráter autônomo (TOYE; TOYE, 2004: 25). Assim, na Carta da ONU, aprovada em junho de 1945, o ECOSOC emerge como um órgão principal, reconhecendo a importância econômica e social da ONU para a reconstrução no pós-guerra. Mas a intenção de fazer com que o Conselho fosse uma parte subsidiária permaneceu em várias partes da Carta, resultando em ambiguidades que afetaram seu mandato desde então.

Por exemplo, o artigo 7 posiciona o ECOSOC como órgão autônomo, enquanto o artigo 60 coloca-o sob a autoridade da AGNU. Já o artigo 62 define ao órgão duas áreas de atuação: os assuntos econômicos e sociais; e os assuntos relacionados aos direitos humanos. Nesses temas, o ECOSOC teria papel de fórum, promovendo relatórios, estudos e conferências, além de recomendar políticas. Tais áreas e funções são muito similares às dadas à AGNU no artigo 13 (ROSENTHAL, 2007: 136-9).

A despeito dessas imprecisões, o aspecto mais característico do ECOSOC é a autoridade de criar corpos especializados (artigo 68) e a responsabilidade de coordenar as atividades das agências especializadas já existentes (artigos 57, 58, 63 e 64). Na Carta, as IBW foram consideradas como agências especializadas, e portanto, estariam sob a supervisão do ECOSOC, que deveria servir como coordenador dessas agências. Legalmente, existe apenas o sistema da ONU, e as IBW estariam subordinadas a essa coordenação.

Mas o ECOSOC, além de não ter sido dotado de grandes instrumentos de coordenação, foi incapaz de exercer qualquer autoridade sobre as IBW, pois essas foram estabelecidas, na prática, fora do arcabouço da ONU. O próprio acordo entre a ONU e o FMI, de 1947, estabelece no artigo I.2 a completa autonomia e separação 
do Fundo em relação à ONU: o FMI deveria ser uma organização independente em função da natureza de suas responsabilidades econômicas, de caráter técnico e especializado ("AGREEMENT...", 1947, trad. nossa).

Logo, além da fragmentação institucional da governança econômica global do pós-guerra, há claramente o interesse, por parte do bloco histórico internacional transatlântico, de separar a ONU das questões discutidas pelas IBW. Como salientam Toye e Toye (2004: 277, trad. nossa), os EUA desde o início estiveram determinados em garantir que a ONU "nunca iria dizer ao Banco Mundial ou ao FMI o que fazer"8. Efetivamente, a autonomia das IBW demonstra que o ECOSOC nunca foi visto como o centro da coordenação econômica global no arranjo do liberalismo inserido.

Mas ainda é necessário explicar os motivos pelos quais a ONU foi relegada a segundo plano pelo bloco histórico liderado pelos EUA. A resposta a essa questão remete ao potencial da ONU em desenvolver mecanismos de resistência por parte das forças sociais excluídas desse arranjo. Essas serão as considerações da última seção.

\section{A contradição do liberalismo inserido e as forças de resistência no interior da ONU}

Mesmo que o papel dos EUA tenha sido central na definição da forma e do conteúdo da ordem do pós-guerra, a emergência da ONU é prova de que esse país não poderia sustentá-la sozinho. Internacionalmente, o compromisso do liberalismo inserido foi expresso pelo princípio da igualdade soberana, legitimado pela Carta da ONU, de modo que, no pós-guerra, configura-se um sistema internacional que realiza de forma mais plena a ideia de Estado nação soberano ${ }^{9}$.

${ }^{8}$ Do original: “(...) was never going to tell the World Bank or the International Monetary Fund what to do".

${ }^{9}$ Devo essa afirmação às considerações feitas em aula pelo professor Sebastião 
Entretanto, os países periféricos, ou subdesenvolvidos, nunca foram plenamente contemplados pelas benesses do liberalismo inserido: a fragmentação da governança econômica global efetivamente garantiu a redução do espaço de barganha que esses países tinham para negociar seus interesses econômicos com o bloco histórico internacional transatlântico.

Porém, esses países efetivamente tentaram superar tais limitações com estratégias de antifragmentação, criando coalizões de resistência (BENVENISTI; DOWNS, 2007: 599). No pós-guerra, essas estratégias foram articuladas pelo Terceiro Mundo ${ }^{10}$, uma importante força política e simbólica que buscou resistir à forma como a governança econômica global cristalizava o poder a favor do bloco histórico internacional transatlântico.

O Terceiro Mundo reunia geograficamente os países do Sul global (continentes sul-americano, africano e asiático), a maior parte recém-descolonizado, e buscava se desvencilhar da dinâmica política e econômica tanto do Primeiro Mundo, formado pelos EUA e a Europa Ocidental, enquadrados no bloco capitalista e protegidos pelo sistema de segurança coletiva da OTAN; quanto do Segundo Mundo, formado pela União Soviética e os países da Europa Oriental sob sua influência.

A plataforma política do Terceiro Mundo foi concretizada na Conferência de Bandung, em 1955. Tratou-se da primeira grande cúpula que uniu Estados intermediários e pequenos, sem a participação dos Estados europeus, dos EUA e da União Soviética. Suas demandas envolviam a independência política, o direito de buscar uma inserção internacional autônoma dos interesses estrangeiros e a solução pacífica dos conflitos ${ }^{11}$.

\section{Velasco e Cruz.}

${ }^{10}$ A expressão foi cunhada pelo Economista Alfred Sauvy, em um artigo à revista O Observador, em 1952, fazendo um paralelo ao Terceiro Estado francês.

${ }^{11}$ Obviamente, a atitude dos EUA em relação ao Terceiro Mundo foi hostil, negando-lhe uma posição de neutralidade na Guerra Fria e buscando medidas mais efetivas para ampliar a dependência com a economia estadunidense, 
$|220|$

O papel da ONU na governança...

A ONU foi o espaço institucional em que se desenvolveu a aliança do Terceiro Mundo. Como expressou o então PrimeiroMinistro indiano e um dos líderes do movimento, Jawaharlal Nehru: "Nós acreditamos que a partir de Bandung, nossa grande organização, a ONU, derivou sua força. Isso significa por sua vez que a Ásia e a África devem desempenhar um papel crescente na condução e no destino da organização mundial"12 (NEHRU apud PRASHAD, 2009: 41, trad. nossa).

Mesmo que institucionalmente afastada de um papel econômico expressivo, a escolha da ONU como o centro de desenvolvimento de estratégias antifragmentação ocorreu em virtude de algumas características próprias dessa organização. Primeiramente, porque a ONU era a mais representativa em número de membros, dando ao Terceiro Mundo uma preponderância numérica nas votações, especialmente na AGNU. Pelo sistema de votação de um país-um voto, o Terceiro Mundo poderia mais facilmente superar a fragmentação ao organizar-se em bloco, conseguindo influenciar o resultado das decisões econômicas no âmbito desse órgão.

Em segundo lugar, a ONU carregava ideologicamente tanto uma perspectiva de autonomia, na qual os Estados teriam o direito e a liberdade de definir seu regime econômico; quanto uma perspectiva universalista no que se refere à responsabilidade das nações, umas para com as outras, na promoção do desenvolvimento econômico: uma espécie de nacionalismo internacional, como define Prashad (2009: 12). Isso dava ao Terceiro Mundo duas vantagens: a de trazer uma agenda autônoma e diversa daquela imposta pelas IBW, que inclua tanto a refutação do imperialismo das antigas metrópoles quanto a busca por medidas econômicas mais

fornecendo auxílio técnico e econômico. Tal estratégia foi bem sucedida em vários casos (PRASHAD, 2009: 38).

${ }^{12}$ Do original: "We believe that from Bandung our great organization, the United Nations, has derived its strength. This means in turn that Asia and Africa must play an increasing role in the conduct and destiny of the world organization". 
inclusivas (como barreiras à liberalização e tratamento especial), que fossem embasadas em tratados e acordos; e a de possibilitar que o Terceiro Mundo negociasse essa agenda com os países desenvolvidos em termos diferentes daqueles definidos no interior das IBW, seguindo os princípios do policentrismo e da negociação. Todas as nações, fortes ou fracas, constituíam-se em centros para si mesmos, e deveriam resolver, pela barganha, as divergências reais entre elas com vistas à redução das desigualdades (AMIN, 2005: 93).

Em terceiro lugar, em seu papel de ator intelectual, a ONU consolidou-se no pós-guerra como agente responsável pela produção de conhecimento, especialmente no campo do desenvolvimento econômico. Esse trabalho intelectual permitiu ao Terceiro Mundo legitimar suas demandas não apenas pelo direito ao desenvolvimento, mas de forma científica. Várias agências da ONU, como a CEPAL, o PNUD e a ONUDI, desenvolveram estudos capazes de provar que barreiras econômicas constituamse na forma mais eficaz de atingir o desenvolvimento industrial (MURPHY, 1983: 62).

A síntese da ONU como espaço privilegiado de resistência do Terceiro Mundo materializou-se na criação da Conferência das Nações Unidas sobre Comércio e Desenvolvimento (UNCTAD), em 1964, e na emergência do Grupo dos 77 (G-77). Por meio desses instrumentos, o Terceiro Mundo passou a pressionar pela constituição de um sistema de proteção das economias nacionais, baseado em um arranjo de preferências comerciais que pudesse estimular a industrialização e o comércio em patamares qualitativamente diferentes.

Como Murphy (1994: 45) destaca, na perspectiva neogramsciana das relações internacionais as organizações internacionais são obras conscientes dos intelectuais. Isso é bem evidente na criação da UNCTAD, que encontrou no trabalho do economista argentino Raul Prebisch - seu primeiro secretáriogeral - uma interpretação política e econômica para as demandas do Terceiro Mundo. A leitura de Prebisch ressaltava o caráter 
estrutural da condição periférica, entendida como resultado direto das políticas dos países centrais, em oposição às teorias da modernização.

Além de contar com uma interpretação teórica que legitimava suas demandas, a UNCTAD consolida um espaço institucional próprio do Terceiro Mundo para buscar uma maior inserção de seus produtos nos mercados dos países desenvolvidos; melhores condições de preço das matérias-primas; e um sistema tarifário especial. Enquanto as IBW e o GATT mantinham tais países praticamente fora das negociações, a UNCTAD permitiu ao Terceiro Mundo negociar melhores termos comerciais na ordem liberal inserida. Como colocado por Prashad (2009: 70, trad. nossa): "A UNCTAD desafiou o poder das corporações globais do Primeiro Mundo e seu direito de senhoriagem sobre os produtos do mundo ex-colonizado"13.

Ao final da primeira conferência da UNCTAD cria-se o G-77, uma coalizão de 77 países em desenvolvimento que defendia um novo quadro do comércio internacional compatível com as necessidades da promoção de uma industrialização acelerada. A atuação do G-77 foi particularmente vitoriosa com a inclusão da Parte IV do GATT, em 1965, que garantia o tratamento especial e diferenciado e a noção de não-reciprocidade comercial para países em desenvolvimento; e com a efetivação do Sistema Geral de Preferências, estabelecido em 1968 e que garantiu tarifas preferenciais para os países em desenvolvimento em uma base não recíproca (THORSTENSEN, 2003: 45).

Como reação ao G-77, o Primeiro e o Segundo Mundos começaram a promover mais intensamente sua própria agenda de desenvolvimento, por meio de ajuda externa governamental. Tal ajuda, obviamente, não permitiu superar os problemas estruturais identificados por Prebisch, mas possibilitou que o G-77 fizesse uma barganha pendular entre os pólos de poder.

\footnotetext{
${ }^{13}$ Do original: "The UNCTAD challenged the power of the First World's global corporations and its droit de seigneur on the products of the formerly colonized world".
} 
A partir desses avanços, a crise econômica que se inicia com a saída unilateral dos EUA do arranjo de Bretton Woods em 1971 permitiu ao Terceiro Mundo usar a oportunidade para finalmente propor uma nova ordem econômica internacional (NOEI) em 1974, por ocasião da $6^{a}$ Reunião Extraordinária da AGNU, convocada pela Argélia, então presidente do Movimento dos Não-Alinhados ${ }^{14}$. No final da reunião, dois documentos basilares foram aprovados: a Declaração sobre o Estabelecimento da Nova Ordem Econômica Internacional, que apontava os princípios gerais que deveriam guiar a nova ordem, como a equidade, a igualdade soberana, a interdependência, o interesse comum e a cooperação entre os Estados; e o Programa de Ação sobre o Estabelecimento da Nova Ordem Econômica Internacional, que traduzia os princípios da declaração em medidas concretas, como a correção das assimetrias econômicas entre os países e a garantia do desenvolvimento econômico e social acelerado.

Como reflexo dessa sessão extraordinária, a $29^{a}$ Sessão Ordinária da AGNU, ocorrida naquele mesmo ano, aprovou a Carta dos Direitos e Deveres Econômicos dos Estados, que estabelecia um quadro legal para tornar a NOEI efetiva. Afirmava que cada Estado tinha o direito de regulamentar os investimentos estrangeiros nos limites de sua jurisdição nacional, inclusive de nacionalizar e expropriar, e de agrupar-se em organizações de produtores de bens de base com vistas a desenvolver sua economia nacional.

A proposta da NOEI visava superar a exclusão do Terceiro Mundo das decisões mais importantes referentes à governança econômica global, a partir da democratização de suas instituições. Isso seria feito tanto pela canalização do apoio da opinião pública, para que os países do Primeiro Mundo pudessem apoiar o desenvolvimento dos países do Terceiro Mundo; quanto por reformas no processo decisório das instituições, tornando-as

14 O Movimento dos Não-Alinhados foi criado em 1961, agrupando um conjunto de países contrários ao alinhamento com uma das grandes potências do conflito bipolar e que promoviam uma política independente fundada na coexistência pacífica. 
|224 |

O papel da ONU na governança...

mais democráticas, seguindo o princípio de um país-um voto. Murphy (1983: 75) aponta que, embora os dois sentidos sejam contraditórios (pois o primeiro coloca como base legítima das decisões políticas a soberania popular, e o segundo, a soberania estatal), ambos expressam a ideologia da NOEI em articular uma mudança estrutural do poder:

Os Estados do Sul não invocaram esse argumento porque os governos do Terceiro Mundo estavam apenas buscando maior poder coletivo sobre as relações econômicas internacionais. Eles também buscavam um mundo onde os Estados teriam direitos e deveres econômicos iguais, o mundo que eles queriam desde o final da II Guerra. E eles permaneceram bastante dispostos a justificar suas propostas com seus princípios fundamentais, apesar do fato de que os governos do Norte rejeitassem sua força moral ${ }^{15}$ (MURPHY, 1983: 66, trad. nossa).

Em suma, a NOEI foi muito mais do que uma aliança mercantilista do Terceiro Mundo para ampliar seu poder político e econômico na ordem do pós-guerra. Além das demandas por maior regulação econômica já realizadas por esse grupo, há algo de inédito na proposta, pois trata-se do resultado de uma nova ideologia que emerge das entranhas das contradições da ordem então estabelecida. E como uma nova ideologia, consolida de forma definitiva a consciência do Terceiro Mundo de que o arranjo do liberalismo inserido era claramente limitador de suas demandas, sendo, portanto, necessárias novas linhas de ação, envolvendo efetivamente a proposta de uma nova ordem econômica

\footnotetext{
${ }^{15}$ Do original: "Southern states did not invoke that argument because Third World governments were not only seeking more collective power over international economic relations. They were also still seeking that world where states would have those equal economic rights and duties, the world they had wanted since the end of World War II. And they remained quite willing to justify their proposals with their fundamental principles despite the fact that Northern governments rejected their moral force".
} 
internacional como forma de superar os constrangimentos que a fragmentação institucional impunha aos seus interesses.

\section{Conclusão}

São conhecidos os rumos da ordem econômica internacional após a dissolução do liberalismo inserido. Ao invés da democratização da governança econômica global, como ansiava o Terceiro Mundo por meio da NOEI, a década de 1980 é marcada pelo violento movimento do bloco histórico internacional transatlântico de antagonismo e desarticulação da solidariedade e das demandas terceiro mundistas. Institucionalmente, isso foi feito pelos mecanismos decisórios do FMI, do Banco Mundial e do GATT (que se transformaria em OMC ao final da Rodada Uruguai, em 1994), sobre os quais o bloco liderado pelos EUA detinha total controle. Os países do Terceiro Mundo foram enquadrados principalmente por meio das reformas estruturais supervisionadas por essas instituições, ocorridas em virtude da crise da dívida (TOYE; TOYE, 2004: 278).

Na ONU, os países desenvolvidos utilizaram a estratégia de se retirar ou de cortar os recursos das agências que tinham programas importantes nos países em desenvolvimento, de modo que o peso numérico do Terceiro Mundo na ONU não era suficiente para contornar a estrutura de governança que claramente favorecia o bloco transatlântico. Ademais, as fissuras de classe no interior dos países do Terceiro Mundo foram exploradas para reatar, por meio de suas elites, os laços de dependência com o Primeiro Mundo.

Tais desdobramentos posteriores à proposta da NOEI mostravam que o liberalismo inserido havia desmoronado. Embora a especificidade dessa ordem estivesse em seu compromisso de classe - em que os Estados puderam regular as atividades do mercado por uma rede de restrições sociais e políticas - os termos plenos dessa ordem apenas foram acessados pelos países que compunham o bloco histórico internacional transatlântico. Para 
o restante do mundo, os nexos institucionais articulados pela fragmentação das IBW davam a esse bloco o poder de garantir a liberalização econômica global.

As estratégias de resistência no âmbito da ONU revelaram seu caráter limitado, por se tratar de uma organização que já tinha um papel secundário na governança econômica do período. Mas não se pode minimizar a importância das fissuras politicamente exploradas pelos países do Terceiro Mundo, uma vez que seu aglutinamento ideológico fez avançar a batalha entrincheirada por uma outra ordem, que fosse diferente do liberalismo inserido. Um dos resultados mais importantes dessa luta foi a manutenção da ideologia onusiana, diferenciada das IBW. Enquanto na década de 1990 essas passaram a oferecer soluções de livre mercado para os problemas do desenvolvimento, as agências da ONU continuaram operando sob a crença de que a intervenção pública nacional e internacional é necessária para permitir que o desenvolvimento humano seja cumprido.

Por fim, episódios contemporâneos - como as discussões sobre a reforma da ONU; a gestão mundial da crise de 2008, em que, mais uma vez, os EUA e os países europeus negaram à ONU o papel de um fórum legítimo para a solução da crise; e a emergência de novas coalizões que de certa forma resgatam o espírito terceiro-mundista, como os BRICS - demonstram a importância de se recuperar historicamente o papel que a ONU ocupou, e, principalmente, que deveria ocupar na luta por uma nova ordem econômica internacional.

\section{Referências}

AGREEMENT between the United Nations and the International Monetary Fund. 15 nov. 1947. In: INTERNATIONAL MONETARY FUND. The International Monetary Fund 19451975. Vol. III - Documents. Washington D.C., 1969. Disponível em: <http://goo.gl/wX198U >. Acesso em: 13 jul. 2014. 
AMIN, S. Que futuro terão as Nações Unidas? In: Revista Política Externa, Vol. 14, no. 2, Set/Out/Nov, 2005, pp. 87-112.

BENVENISTI, E.; DOWNS, G. The Empire's new clothes: Political Economy and the Fragmentation of International Law. Stanford Law Review, v 60, n 2, 2007, pp. 595-631.

GILL, S.; LAW, D. Hegemonia global e poder estrutural do capital. In: GILL, S. (Org.). Gramsci, materialismo histórico e relações internacionais. Rio de Janeiro: Editora UFRJ, 2007, pp. 157-197.

GWIN, C. U.S. Relations with the World Bank, 1945-1992. In: KAPPUR, S. et al. (Orgs.). The World Bank - Its First Half Century. Washington: The Brookings Institution, 1997, pp. 195-274.

KINDLEBERGER, C. The world in depression (1929-1939). Califórnia: University of California Press, 1973.

KRASNER, S. Structural causes and regime consequences: regimes as intervening variables. In: Ithaca: Cornell University Press, 1983.

LICHTENSZTEJN, S.; BAER, M. Fundo Monetário Internacional e Banco Mundial: estratégias e políticas do poder financeiro. São Paulo: Brasiliense, 1987.

MURPHY, C. What the Third World Wants: An Interpretation of the Development and Meaning of the New International Economic Order Ideology. International Studies Quarterly, v. 27, n. 1, mar. 1983.

MURPHY, C. International Organization and Industrial Change: Global Governance since 1850. Cambridge: Polity Press, 1994.

PRASHAD, V. The darker nations: a people's history of the Third World. Nova Iorque, Londres: The New Press, 2009.

ROSENTHAL, G. Economic and Social Council. In: WEISS, T. G.; DAWS, S. (Orgs.). The Oxford Handbook on the United Nations. Oxford: Oxford University Press, 2007, pp. 136-148. 
O papel da ONU na governança..

RUGGIE, J. International regimes, transactions and change: embedded liberalism in the postwar economic order. In: KRASNER, S. D. (Org.). International Regimes. Ithaca e Londres: Cornell University Press, 1983, pp. 195-231.

SEITENFUS, R. Manual das Organizações Internacionais. 5ª Edição. Porto Alegre: Livraria do Advogado, 2012.

THORSTENSEN, V. Organização Mundial do Comércio: as regras do comércio internacional e a nova rodada de negociações multilaterais. São Paulo: Aduaneiras, 2003.

TOYE, J.; TOYE, R. The UN and Global Political Economy: Trade, Finance and Development. Indiana: Indiana University Press, 2004.

VELASCO E CRUZ, S. Comércio Internacional em um mundo partido: o regime do GATT e os países em desenvolvimento. Cadernos CEDEC, no. 77, ago. 2005. 